\title{
Editorial
}

\section{Tissue Grafting and Allograft May Bring About a Revolution in Rehabilitation}

\author{
ASMJ Chwdhury ${ }^{1}$, AR Mondal ${ }^{2}$
}

Urbanization, industrialization and quick transportation are essential for development of a country and progress of a nation. Bangladesh is trying to its level best to become moderate earning country. Injuries due to various kinds of accident especially the industrial and road traffic accident (RTA) are very rapidly increasing. The patterns of accident are also changed due to modern heavy machines in the industries and high velocity heavy vehicles in narrow roads. Burn is another burning issue. Injury due to burn is occurring regularly, massively and severely as a result of unplanned factories specially the garment factories. Firing petrol bombs on public bus by the terrorists is another addition to this. All these are creating disability. Thus, the disability in our country is increasing rapidly.

Rehabilitation means to have normal useful life after recovery from illness which includes physical rehabilitation as well as vocational and socioeconomical rehabilitation. We medical persons can contribute by playing role in physical rehabilitation. Healthy skin coverings and healthy locomotor system are essential for movements and physical activities. In burn and road traffic accident, skin and many of the components of locomotor system are damaged. Sometimes, these damages are massive and irreparable. For physical rehabilitation, anatomical continuity of skin and components of locomotor system are essential. For these various types of grafting, plastic surgery, reconstructive surgery, replantation surgery, orthosis, prosthesis etc developed. All these procedures need experts, special equipments and set up. Among these, skin and bone grafting patients comprises the major bulk, procedures are also relatively easier but unavailability of graft is a problem especially when it requires a massive amount.

Grafting means transfer of tissue from one place to another either in same individual (autograft) or in different individual of same species (allograft) or another species (xenograft) to repair the defect. The partial and full thickness skin grafts are revascularised by the in growth of capillary buds from the underlying

1. Dr. ASM Jahangir Chowdhury, MBBS, MS (Orthopaedic surgery), Professor and head of the department, Department of Orthopeadic surgery, Faridpur Medical College, Faridpur and Principal, Faridpur Medical College..

2. Dr. Anadi Ranjan Mondal, MBBS, MCPS (Surgery), MS (Orthopaedic surgery), Assistant Professor, Department of Orthopeadic surgery, Faridpur Medical College, Faridpur.

Address of correspondence :

Dr. ASM Jahangir Chowdhury, MBBS, MS (Orthopaedic surgery), Professor and head of the department, Department of Orthopeadic surgery, Faridpur Medical College, Faridpur and Principal, Faridpur Medical College. Mobile: +88-01711875535,

Email: mrittika_fpur@yahoo.com tissues $^{1}$. Bone grafts act by osteoinductiion as well as osteoconduction. Osteoinduction means stimulation of osteogenesis by few viable osteoprogenitor cells and bone morphogenetic protein (BMP) the graft matrix contain $^{2}$. Osteoconduction means bridging of the bony defect with bone graft which act as scaffold upon which new bone can form. Vascularised grafts remain completely viable and incorporated by a process analogous to fracture healing. Nonvascularised grafts undergo necrosis; though a few surface cells remain viable, stimulate an inflammatory response with the formation of a fibrovascular stroma through which blood vessels and osteoprogenetor cells pass from the recipient bone to the graft. Autografts are the most commonly and satisfactorily used grafts but in many cases they are insufficient and inappropriate for the purpose regarding shape, size, sites etc. Allografts can be stored in bone bank, plentiful, large enough and can be shaped accordingly. But though dead, fresh allografts are not immunologically acceptable and may lead to rejection. Antigenicity can be reduced by freezing, freeze-drying, demineralization, or by ionizing radiation. Sterility of the graft is ensured by exposure to ethylene oxide or by ionizing radiation, but physical properties of the graft and potential for osteoinduction considerably altered ${ }^{3,4}$. When harvested under sterile condition freezing and storing at -70 degree Centigrade is much less harmful but the donor must be free of malignancy, Venereal Disease, HBV and HIV.

Tissue Banking is the retrieval, processing, storage and distribution of viable or nonviable tissues of human or animal origin for medical uses, and the formally organized entities conducting such activities are termed Tissue Bank. Tissue Banks are a new frontier for biomolecular research, clinical genomics and medicine that seeks to integrate collection of bio-specimens for banking human cells and tissues include arteries, bones, cartilage, bone marrow, cornea, duramater, fascialata, heart-valves, pericardium, semen, skin, amniotic membrane etc. Bangladesh Atomic Energy Commission (BAEC) owns the only Tissue Bank in Bangladesh and works in auspices with the peaceful use of nuclear technology in healthcare sector.

Research and development activities on tissue banking in Bangladesh were initiated in 1985 at the Atomic Energy Research Establishment (AERE), Savar, Dhaka, in co-operation with the International Atomic Energy Agency (IAEA). It was instigated with the aim to develop the protocol for processing of human amniotic membrane and bone tissues. Tissue Banking Laboratory is now upgraded as an independent unite at AERE by 
the name of Tissue Banking and Biomaterial Research Unite (TBBRU). Following types of tissue allografts are collected, processed and supplied for clinical application by TBBRU with the participation of related surgeons throughout the country: (i) Freeze/oven radiation amnion allograft for burn dressing, healing wound, bed sore, diabetic wound, leprotic ulcer etc. (ii) Cryopreserved amnion allograft for corneal ulcer, cornel transplantation, limbal cell deficiency, pterygium excision site etc. (iii) Freeze dried bone allograft for traumatic bone loss, gap nonunion, gap after excision of a bone cyst or bone tumour, replacement arthroplasty, spinal reconstruction, oral and maxillofacial reconstruction etc. Till to date about 35,000 pieces of amniotic membrane and about $55,000 \mathrm{cc}$ bone grafts have been prepared and supplied to rehabilitate about 65,000 patients with an involvement of more than 400 surgeons from 130 hospitals throughout the country.

Anatomical continuity and full functional recovery are the aim of our all treatment. So that the patient may return to his previous job quickly and there by establish his position in his family and in the society. Healthy skin coverings and locomotors system are essential for movements and physical activities. In many diseases and accidents these become defective. Verities of plastic and reconstructive surgery developed to repair these defects. In massive burn, to repair the defect there is no scope of auto skin graft due to its unavailable donor sites. In this case, freeze/oven dried radiation amnion allograft is the only suitable tool. Vascularized grafts are required in many cases of skin repair and in some special circumstances of bone defect like psudoarthrosis of tibia, gap nonunion of long bones etc. But the technique is difficult and time consuming, requiring micro surgical skill. In cases of allografts there is question of compatibility. Nonvascularized cortical or corticocancellous grafts are needed where a segment of bone has been lost as a result of trauma or has been removed because it contained tumor. Cancellous grafts have a wide verity of uses, including: filling cavities and space, augmenting internal fixation of long bone fractures and atrophic nonunion, in hip surgery to augment acetabular defect and femoral medullary space, fusion of spine and so one. Small cavities and little defects can be filled up with autografts. When large cavities or defects have to be filled, properly stored allografts in Tissue Bank are useful. Amniotic membrane, allogenic bone grafts in cancellous as well as in cortical and cortico-cancellous forms are available in Tissue Bank, TBBRU, BAEC, Saver, Dhaka.

According to police report total number of road traffic accident was 40,927 in Bangladesh during period of 2001-2010. Number of killed person was 32,261, and number of injured was 41 times of this. This is increasing by a rate of $65 \%$ to $80 \%$ in each year ${ }^{5}$. There is only one TBBRU at BAEC in Savar, Dhaka conducting its activities only in and around Dhaka. It is not enough to ful fill the total need of the country for rehabilitation of the disabled from burn and accident. All the surgeons especially of the remote districts are not oriented about the tissue banking. All the related doctors should be involved in collecting the tissue and in proper application of the processed grafts. The BAEC should extend its TBBRU in all medical college hospitals. At least logistic and one trained agent should be available in all district hospital for proper collection, preservation and transportation of the graft tissue. Government and related NGOs should also come forward for financial support, mass contact, publicity, broad casting and public motivation for tissue donation under the "Organ and Tissue Transplantation Act 05/1999". So, spread of Tissue Banking activity throughout the country may bring about a revolution in reducing the physically disabled.

\section{References :}

1. Rosin RD. Burn. In: Mann CV, Russell RCG, editors. Bailey \& Love's Short Practice of Surgery. Twenty First Editions. London. ELBS; 1991. P 157-93.

2. Urist MR. Bone formation in implants of partially and wholly demeneralized bone matrix. Clinical Orthopaedics and related Research 1970; 71:271-78.

3. Friedlaender GE. Bone grafts. Journal of Bone and Joint Surgery 1987; 69A:786-90.

4. Aspenberg P, Johnsson E, Thirngren KG. Dose-dependent reduction of bone inductive properties by ethylene oxide. Journal of Bone and Joint Surgery 1990; 72B:1036-37.

5. Nade S, Burwell RG. Decalcified bone as a substrate for osteogenesis. Journal of Bone and Joint Surgery 1977; 59B:189-96.

6. Chowdhury ASMJ, Alam MS, Biswas SK, Saha RK, Mondal AR, Rahman MM et al. Road Traffic Accident by Nasimon and Karimon-A Study of Faridpur Medical College Hospital. Faridpur Medical College Journal 2012; 7(1):06-09. 